\title{
Thermal Conductivity of $\beta-\mathrm{Si}_{3} \mathrm{~N}_{4}$ : II, Effect of Lattice Oxygen
}

\author{
Mikito Kitayama ${ }^{* \dagger}$ \\ Synergy Ceramics Laboratory, Fine Ceramics Research Association, 2268-1 Shimo-Shidami,
} Nagoya, Aichi 463-8687, Japan

\author{
Kiyoshi Hirao, ${ }^{\star}$ Akira Tsuge, Koji Watari, ${ }^{*}$ Motohiro Toriyama, and Shuzo Kanzaki ${ }^{\star}$ \\ National Industrial Research Institute of Nagoya (NIRIN), 2268-1 Shimo-Shidami, Nagoya, Aichi 463-8687, Japan
}

\begin{abstract}
Dense $\beta-\mathrm{Si}_{3} \mathrm{~N}_{4}$ with various $\mathrm{Y}_{2} \mathrm{O}_{3} / \mathrm{SiO}_{2}$ additive ratios were fabricated by hot pressing and subsequent annealing. The thermal conductivity of the sintered bodies increased as the $\mathrm{Y}_{2} \mathrm{O}_{3} / \mathrm{SiO}_{2}$ ratio increased. The oxygen contents in the $\beta-\mathrm{Si}_{3} \mathrm{~N}_{4}$ crystal lattice of these samples were determined using hot-gas extraction and electron spin resonance techniques. A good correlation between the lattice oxygen content and the thermal resistivity was observed. The relationship between the microstructure, grain-boundary phase, lattice oxygen content, and thermal conductivity of $\boldsymbol{\beta}-\mathrm{Si}_{3} \mathrm{~N}_{4}$ that was sintered at various $\mathrm{Y}_{2} \mathrm{O}_{3} / \mathrm{SiO}_{2}$ additive ratios has been clarified.
\end{abstract}

\section{Introduction}

$\mathrm{O}$ UR previous work investigated the effects of various microstructural factors (grain size, thickness of the grain-boundary film, and alignment of elongated grains) of $\beta-\mathrm{Si}_{3} \mathrm{~N}_{4}$ ceramics on thermal conductivity. ${ }^{1}$ Theoretically and experimentally, it was demonstrated that mere grain growth cannot improve thermal conductivity, because of the unique faceting nature of this material. However, it might be possible to improve the thermal conductivity of $\beta-\mathrm{Si}_{3} \mathrm{~N}_{4}$ significantly by reducing the lattice defects, ${ }^{2}$ especially the content of oxygen that is dissolved in the crystal lattice, as has been shown for AIN ceramics. Since a quantitative correlation between the concentration of oxygen dissolved in the lattice of single-crystal AlN and thermal conductivity was given by Slack and co-workers, ${ }^{3,4}$ there have been several additional studies of AIN polycrystals. ${ }^{5-7}$ To date, there has been no report on the effect of lattice oxygen on the thermal conductivity of $\beta-\mathrm{Si}_{3} \mathrm{~N}_{4}$ ceramics. Oxygen is well-known to dissolve in the $\alpha-\mathrm{Si}_{3} \mathrm{~N}_{4}$ crystal lattice. ${ }^{8}$ However, the fact of whether or not oxygen dissolves in the $\beta-\mathrm{Si}_{3} \mathrm{~N}_{4}$ crystal latticeand if so, how much-never has been reported.

Recently, we reported on the lattice oxygen content of crystalline $\beta-\mathrm{Si}_{3} \mathrm{~N}_{4}$ using the hot-gas extraction method, ${ }^{9}$ which has been proven successful in analyzing the lattice oxygen content of AlN ceramics. ${ }^{10}$ The pure $\beta-\mathrm{Si}_{3} \mathrm{~N}_{4}$ crystal was fabricated via heat treatment of $\alpha-\mathrm{Si}_{3} \mathrm{~N}_{4}$ powder with sintering additives, and the

R. A Cutler-contributing editor

\footnotetext{
Manuscript No. 189239. Received July 12, 1999; approved January 26, 2000.

Supported by AIST, MITI, Japan, as part of the Synergy Ceramics Project. This work has been supported in part by NEDO. The authors are members of the Joint Research Consortium of Synergy Ceramics.

Presented at the 51st Pacific Coast Regional Meeting of the American Ceramic Society (Oct. 27-29, 1999, Bellevue, WA), "International Symposium on High Thermal Conductivity Materials: Fundamentals and Applications" (Basic Science Division and Electronics Division).

${ }^{*}$ Member, American Ceramic Society.

Author to whom correspondence should be addressed. Now with Functional Materials Engineering Department, Fukuoka Institute of Technology, Fukuoka 811-0295, Japan.
}

secondary phase was removed through acid treatments. The oxygen contents were reported to be $0.258 \pm 0.006$ and $0.158 \pm$ $0.003 \mathrm{wt} \%$. However, this method has not yet been applied to dense $\beta-\mathrm{Si}_{3} \mathrm{~N}_{4}$ ceramics. In $\mathrm{AlN}$, the electron spin resonance (ESR) method also has been shown to be effective for analyzing lattice defects that are caused by oxygen dissolution. ${ }^{11}$ The number of spins caused by electrons trapped by nitrogen vacancies was inversely proportional to the lattice oxygen content and, thus, had a good correlation with thermal conductivity. It is expected that the ESR analysis method also could be applied to $\beta-\mathrm{Si}_{3} \mathrm{~N}_{4}$.

In AlN ceramics that have been sintered with $\mathrm{Y}_{2} \mathrm{O}_{3}$, the $\mathrm{Y}_{2} \mathrm{O}_{3}$ functions as a sintering aid to allow liquid-phase sintering and reduce the lattice oxygen via the formation of $\mathrm{Al}_{2} \mathrm{O}_{3}-\mathrm{Y}_{2} \mathrm{O}_{3}$ phases. Thus, the ratio of $\mathrm{Y}_{2} \mathrm{O}_{3}$ and $\mathrm{Al}_{2} \mathrm{O}_{3}\left(\mathrm{Y}_{2} \mathrm{O}_{3} / \mathrm{Al}_{2} \mathrm{O}_{3}\right)$, the latter of which is derived from the oxygen impurities in the raw powder, and, hence, the nature of the second phase were crucial for controlling the lattice oxygen content. ${ }^{5-7}$ Increasing the $\mathrm{Y}_{2} \mathrm{O}_{3}$ l $\mathrm{Al}_{2} \mathrm{O}_{3}$ ratio results in a change of the grain-boundary phase, from $\mathrm{Y}_{3} \mathrm{Al}_{5} \mathrm{O}_{12}$ (YAG) to $\mathrm{YAlO}_{3}$ (YAP) to $\mathrm{Y}_{4} \mathrm{Al}_{2} \mathrm{O}_{9}$ (YAM), a decrease in the lattice oxygen content, and an increase in the thermal conductivity. ${ }^{6}$ In all cases, $\mathrm{Y}_{2} \mathrm{O}_{3}$ was responsible for the reduction of the lattice oxygen. Thus, the ratio of $\mathrm{Y}_{2} \mathrm{O}_{3}$ and $\mathrm{SiO}_{2}\left(\mathrm{Y}_{2} \mathrm{O}_{3} /\right.$ $\mathrm{SiO}_{2}$ ), the latter of which has been derived from the oxygen impurities in the raw powder, also is expected to have a possibly significant effect on the thermal conductivity of $\beta-\mathrm{Si}_{3} \mathrm{~N}_{4}$. The purpose of this work is to investigate the effect of the $\mathrm{Y}_{2} \mathrm{O}_{3} / \mathrm{SiO}_{2}$ additive ratio and, hence, the effect of the lattice oxygen content on the thermal conductivity of $\beta-\mathrm{Si}_{3} \mathrm{~N}_{4}$. Two methods-hot-gas extraction and ESR - have been combined to analyze and quantify the lattice defects of $\beta-\mathrm{Si}_{3} \mathrm{~N}_{4}$ ceramics with various $\mathrm{Y}_{2} \mathrm{O}_{3} / \mathrm{SiO}_{2}$ additive ratios. The effects of various microstructural factors of $\beta-\mathrm{Si}_{3} \mathrm{~N}_{4}$ ceramics on the thermal conductivity were clarified in the previous work ${ }^{1}$ therefore, isolation of the effect of the lattice oxygen content in this work is now possible.

\section{Experimental Procedure}

Commercial $\alpha-\mathrm{Si}_{3} \mathrm{~N}_{4}$ powder (Product $\mathrm{SN}-\mathrm{E} 05$, specific surface area of $4-6 \mathrm{~m}^{2} / \mathrm{g}$, oxygen content of $0.84 \mathrm{wt} \%$; UBE Industries, Ltd., Yamaguchi, Japan) was mixed with $\mathrm{Y}_{2} \mathrm{O}_{3}$ and $\mathrm{SiO}_{2}$ powders (purity of $>99.9 \%$, specific surface areas of 27 and $140 \mathrm{~m}^{2} / \mathrm{g}$, respectively; Hokko Chemicals, Tokyo, Japan) in a resin-coated ball mill for $3 \mathrm{~h}$, using methanol as a mixing medium. The molar ratios of the $\mathrm{Si}_{3} \mathrm{~N}_{4}: \mathrm{Y}_{2} \mathrm{O}_{3}: \mathrm{SiO}_{2}$ mixtures were 40:1:2, 40:2:1, 40:2.5:0.5, and 40:3:0; these mixtures were designated as samples Y1, Y2, Y3, and Y4, respectively. Each slurry was dried using a rotary evaporator at a temperature of $60^{\circ} \mathrm{C}$, subsequently dried at $110^{\circ} \mathrm{C}$ for $2 \mathrm{~h}$, and passed through a 60 mesh nylon sieve. Thirty grams of each powder mixture was charged into a high-purity graphite dye (Toyotanso Co., Osaka, Japan) that was $30 \mathrm{~mm}$ in diameter and coated with high-purity BN powder (GP grade, Denki Kagaku Kogyo Co., Tokyo, Japan); the powder mixture then was hot-pressed at $1800^{\circ} \mathrm{C}$ for $2 \mathrm{~h}$, under a pressure of 40 


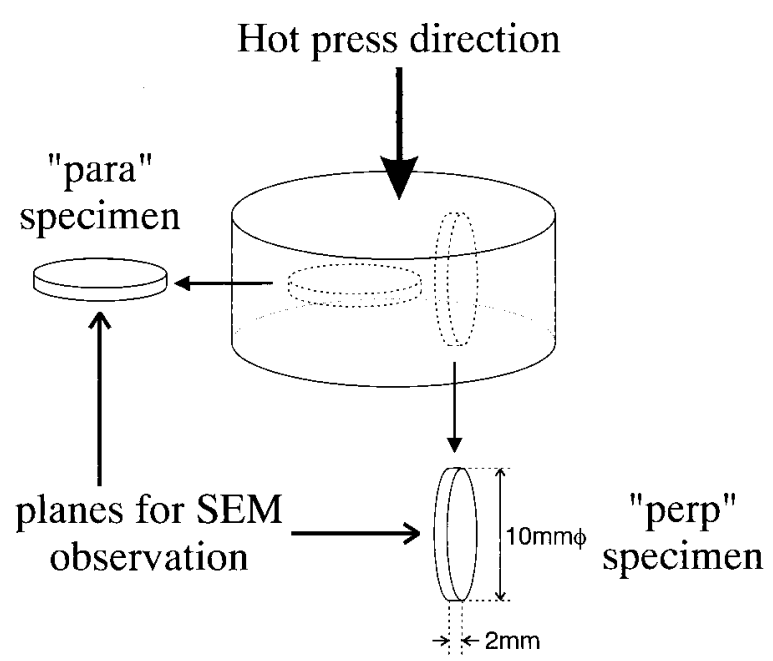

Fig. 1. Illustration showing how the disk specimens (10 $\mathrm{mm}$ in diameter, $2 \mathrm{~mm}$ thick) were obtained from the sintered samples.

$\mathrm{MPa}$ in a flowing nitrogen atmosphere. This procedure resulted in sintered bodies with a relative density of $>99 \%$. Hot-pressed sintered bodies subsequently were annealed at $1850^{\circ} \mathrm{C}$ for $4 \mathrm{~h}$ under a nitrogen pressure of $1 \mathrm{MPa}$ in a high-purity BN crucible (N1 grade, Denki Kagaku Kogyo Co.) with a mixed powder bed of $\mathrm{Si}_{3} \mathrm{~N}_{4}$ (Product SN-E10, UBE Industries, Ltd.) and BN (GP grade, Denki Kagaku Kogyo) $\left(\mathrm{Si}_{3} \mathrm{~N}_{4} / \mathrm{BN}\right.$ ratio of $\left.7: 3\right)$. The hot pressing and annealing were conducted in a furnace with graphite-heating elements that had never been used for materials that contained aluminum. This effort, combined with the use of a resin-coated ball mill and a high-purity graphite dye, evidenced the extreme care that was taken to avoid any possible contamination. Phase identification of the sintered bodies was performed using X-ray diffractometry (XRD) $(\mathrm{Cu} K \alpha$ radiation, operating conditions of 40 $\mathrm{kV}$ and $100 \mathrm{~mA}$, receiving slit width of $0.3 \mathrm{~mm}$ ). The specimen densities were determined via the Archimedes method.

Disk specimens (10 $\mathrm{mm}$ in diameter and $2 \mathrm{~mm}$ thick) that were made to measure the thermal diffusivity $(\alpha)$ were taken parallel and perpendicular to the hot-pressed surfaces from all the sintered samples and finished using a $74 \mu \mathrm{m}$ diamond wheel: these samples were called the "para" and "perp" specimens, respectively (see Fig. 1). The thermal diffusivity was measured at room temperature, using the laser-flash method (Model TC-3000, ULVAC, Yokohama, Japan) after both sides of specimens were coated with a layer of gold $600 \AA$ thick and, subsequently, a layer of black carbon. The thermal conductivity $(\kappa)$ was calculated according to the equation

$$
\kappa=\rho C_{\mathrm{p}} \alpha
$$

where $\rho$ is the density and $C_{\mathrm{p}}$ is the specific heat. A constant value of the specific heat $-C_{\mathrm{p}}=0.7 \mathrm{~J} \cdot(\mathrm{g} \cdot \mathrm{K})^{-1}$-was used in this work. Following the measurements of $\alpha$, all the specimens were surfacefinished with a $1 \mu \mathrm{m}$ diamond slurry, plasma-etched in $\mathrm{CF}_{4}$ gas, coated with a layer of gold $200 \AA$ thick, and investigated via scanning electron microscopy (SEM) (Model JSM-6340F, JEOL, Tokyo, Japan). Mean grain sizes were determined from the SEM micrographs, using the linear-intercept method.

One gram of each sintered body was ground using a WC ball mill for $10 \mathrm{~min}$, dispersed in $50 \mathrm{~mL}$ of methanol, passed through a 500 mesh $(25 \mu \mathrm{m})$ sieve (to remove a trace amount of coarse particles), and dried at a temperature of $60^{\circ} \mathrm{C}$. Each powder was treated first with $50 \% \mathrm{HF}$ at $60^{\circ} \mathrm{C}$ for $3 \mathrm{~h}$ and then with $50 \%$ $\mathrm{H}_{2} \mathrm{SO}_{4}$ at $120^{\circ} \mathrm{C}$ for $2 \mathrm{~h}$, to remove the grain-boundary phase and possible fluoride compounds, respectively. After washing three times in distilled water, using a centrifugal sedimentation method, each powder was dried at $110^{\circ} \mathrm{C}$ for $12 \mathrm{~h}$ and passed through a 100 mesh $(150 \mu \mathrm{m})$ nylon sieve. A commercial hot-gas extraction analyzer (Model TC-436, LECO Co., St Joseph, MI) was used for oxygen and nitrogen determinations. Approximately $20 \mathrm{mg}$ of each dried powder sample was weighed into a graphite crucible $(10 \mathrm{~mm}$ in diameter, $16 \mathrm{~mm}$ deep), and $\sim 200 \mathrm{mg}$ of graphite powder (Product 501-073, LECO Co.) was added to the sample to accelerate the carbothermal reduction of the oxide phases. The crucible was heated to $2500^{\circ} \mathrm{C}$ in $5 \mathrm{~min}$ in a flowing argon atmosphere. The release of oxygen and nitrogen, as a function of temperature, and the total concentrations of oxygen and nitrogen were recorded. A total of three measurements were performed for each sample.

Each sintered body also was cut into a bar shape $4 \mathrm{~mm}$ in diameter and $10 \mathrm{~mm}$ long. ESR measurements were performed at room temperature using an X-band (frequency of $9.0 \mathrm{GHz}$ ) spectrometer (Model E-12 ESR, Varian, Palo Alto, CA). The microwave power was $20 \mu \mathrm{W}$, and the magnetic-field modulation and its amplitude were $100 \mathrm{kHz}$ and $0.05 \mathrm{mT}$, respectively. The $g$-values were determined by comparison with a 2,2-diphenyl-1picrylhydrazyl (DPPH) standard solution in benzene. The number of spins was determined via double integration of the derivative absorption signals and comparison of them with that of a DPPH standard solution in benzene.

\section{Results}

\section{(1) Grain-Boundary Phase}

Table I summarizes the results of the XRD phase identification for samples $\mathrm{Y} 1-\mathrm{Y} 4$. The $\mathrm{Y}_{2} \mathrm{O}_{3} / \mathrm{SiO}_{2}$ additive ratios that have been calculated from the oxygen content of the $\alpha-\mathrm{Si}_{3} \mathrm{~N}_{4}$ raw powder, and those of the grain-boundary phases (based on the chemical formulas in the parentheses), also are given in the table. For sample $\mathrm{Y} 1$, the $\mathrm{Si}_{2} \mathrm{~N}_{2} \mathrm{O}$ and $\mathrm{Y}_{2} \mathrm{Si}_{2} \mathrm{O}_{7}$ phases are observed, and the corresponding $\mathrm{Y}_{2} \mathrm{O}_{3} / \mathrm{SiO}_{2}$ ratio is bewteen $0 / 1$ and $1 / 2$. For sample $\mathrm{Y} 2$, the $\mathrm{Y}_{2} \mathrm{Si}_{2} \mathrm{O}_{7}$ and $\mathrm{Y}_{20} \mathrm{~N}_{4} \mathrm{Si}_{12} \mathrm{O}_{48}$ (apatite structure) phases are observed, and the corresponding $\mathrm{Y}_{2} \mathrm{O}_{3} / \mathrm{SiO}_{2}$ ratio is between $1 / 2$ and 10/9. For sample $\mathrm{Y} 3$, only the $\mathrm{Y}_{20} \mathrm{~N}_{4} \mathrm{Si}_{12} \mathrm{O}_{48}$ phase is observed, and the corresponding $\mathrm{Y}_{2} \mathrm{O}_{3} / \mathrm{SiO}_{2}$ ratio is $\sim 10 / 9$. For sample $\mathrm{Y} 4$, the $\mathrm{Y}_{20} \mathrm{~N}_{4} \mathrm{Si}_{12} \mathrm{O}_{48}$ and $\mathrm{Y}_{2} \mathrm{Si}_{3} \mathrm{~N}_{4} \mathrm{O}_{3}$ (melilite structure) phases are observed, and the corresponding $\mathrm{Y}_{2} \mathrm{O}_{3} / \mathrm{SiO}_{2}$ ratio is bewteen $10 / 9$ and $1 / 0$. Thus, the $\mathrm{Y}_{2} \mathrm{O}_{3} / \mathrm{SiO}_{2}$ ratios of the grainboundary phases are confirmed to be very similar to the additive compositions for all the samples. $\mathrm{A} \mathrm{Si}_{3} \mathrm{~N}_{4}-\mathrm{Y}_{2} \mathrm{O}_{3}-\mathrm{SiO}_{2}$ phase diagram at a temperature of $1850^{\circ} \mathrm{C}$ can be constructed schematically from these XRD phase-identification results, as shown in Fig. 2. The $\mathrm{Si}_{3} \mathrm{~N}_{4}-\mathrm{Si}_{2} \mathrm{~N}_{2} \mathrm{O}-\mathrm{Y}_{2} \mathrm{Si}_{2} \mathrm{O}_{7}$ (region I), $\mathrm{Si}_{3} \mathrm{~N}_{4}-\mathrm{Y}_{2} \mathrm{Si}_{2} \mathrm{O}_{7}-$

Table I. Results of Grain-Boundary-Phase Identification via XRD for Samples Y1-Y4

\begin{tabular}{|c|c|c|c|c|c|}
\hline \multirow[b]{2}{*}{ Sample } & \multirow[b]{2}{*}{$\begin{array}{l}\mathrm{Y}_{2} \mathrm{O}_{3} / \mathrm{SiO}_{2} \\
\text { additive ratio }\end{array}$} & \multicolumn{4}{|c|}{ Intensity ${ }^{*}$ of phases present } \\
\hline & & $\begin{array}{c}\mathrm{Si}_{2} \mathrm{~N}_{2} \mathrm{O} \\
\left(\mathrm{SiO}_{2} \cdot \mathrm{Si}_{3} \mathrm{~N}_{4}\right) \\
\mathrm{Y}_{2} \mathrm{O}_{3} / \mathrm{SiO}_{2}=0 / 1\end{array}$ & $\begin{array}{c}\mathrm{Y}_{2} \mathrm{Si}_{2} \mathrm{O}_{7} \\
\left(\mathrm{Y}_{2} \mathrm{O}_{3} \cdot 2 \mathrm{SiO}_{2}\right), \\
\mathrm{Y}_{2} \mathrm{O}_{3} / \mathrm{SiO}_{2}=1 / 2\end{array}$ & $\begin{array}{c}\mathrm{Y}_{20} \mathrm{~N}_{4} \mathrm{Si}_{12} \mathrm{O}_{48} \\
\left(10 \mathrm{Y}_{2} \mathrm{O}_{3} \cdot 9 \mathrm{SiO}_{2} \cdot \mathrm{Si}_{3} \mathrm{~N}_{4}\right) \\
\mathrm{Y}_{2} \mathrm{O}_{3} / \mathrm{SiO}_{2}=10 / 9\end{array}$ & $\begin{array}{c}\mathrm{Y}_{2} \mathrm{Si}_{3} \mathrm{~N}_{4} \mathrm{O}_{3} \\
\left(\mathrm{Y}_{2} \mathrm{O}_{3} \cdot \mathrm{Si}_{3} \mathrm{~N}_{4}\right) \\
\mathrm{Y}_{2} \mathrm{O}_{3} / \mathrm{SiO}_{2}=1 / 0\end{array}$ \\
\hline Y1 & 0.289 & w & w & ND & ND \\
\hline Y2 & 0.807 & ND & W & vw & ND \\
\hline Y3 & 1.267 & ND & ND & $\mathrm{m}$ & ND \\
\hline Y4 & 2.029 & ND & ND & $\mathrm{m}$ & $\mathrm{w}$ \\
\hline
\end{tabular}

"Corrected for the oxygen content of $\alpha-\mathrm{Si}_{3} \mathrm{~N}_{4}$ powder. "The symbol legend for the intensities is as follows: "m," middle; "w," weak; "vw," very weak; and "ND," not detected. 


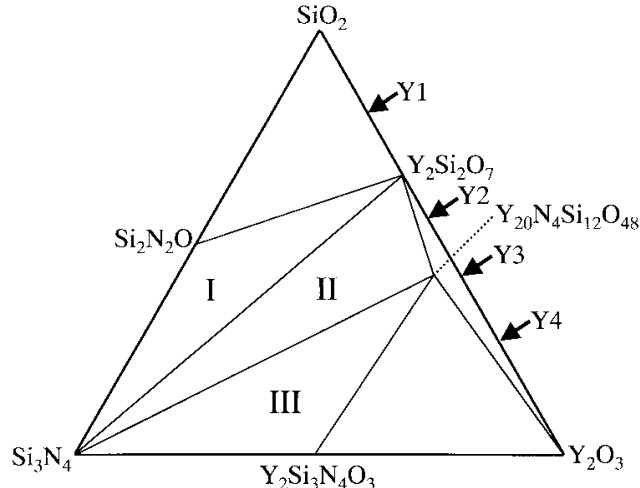

Fig. 2. $\mathrm{Si}_{3} \mathrm{~N}_{4}-\mathrm{Y}_{2} \mathrm{O}_{3}-\mathrm{SiO}_{2}$ phase diagram at $1850^{\circ} \mathrm{C}$, constructed schematically from the XRD phase-identification result. $\mathrm{Y}_{2} \mathrm{O}_{3} / \mathrm{SiO}_{2}$ additive ratios of samples $\mathrm{Y} 1-\mathrm{Y} 4$ are indicated by arrows.

$\mathrm{Y}_{20} \mathrm{~N}_{4} \mathrm{Si}_{12} \mathrm{O}_{48}$ (region II), and $\mathrm{Si}_{3} \mathrm{~N}_{4}-\mathrm{Y}_{20} \mathrm{~N}_{4} \mathrm{Si}_{12} \mathrm{O}_{48}-\mathrm{Y}_{2} \mathrm{Si}_{3} \mathrm{~N}_{4} \mathrm{O}_{3}$ (region III) three-phase fields correspond to the phase compositions of samples $\mathrm{Y} 1, \mathrm{Y} 2$, and $\mathrm{Y} 4$, respectively. The $\mathrm{Si}_{3} \mathrm{~N}_{4}-$ $\mathrm{Y}_{20} \mathrm{~N}_{4} \mathrm{Si}_{12} \mathrm{O}_{48}$ two-phase field corresponds to the phase composition of sample $\mathrm{Y} 3$. The $\mathrm{Y}_{2} \mathrm{O}_{3} / \mathrm{SiO}_{2}$ additive ratios of samples $\mathrm{Y} 1-\mathrm{Y} 4$, in regard to the oxygen content of the raw $\alpha-\mathrm{Si}_{3} \mathrm{~N}_{4}$ powder, also are indicated by arrows in this figure.

\section{(2) Microstructure and Thermal Conductivity}

Figure 3 shows SEM micrographs of polished and etched surfaces of all the samples. All micrographs are for the "para"
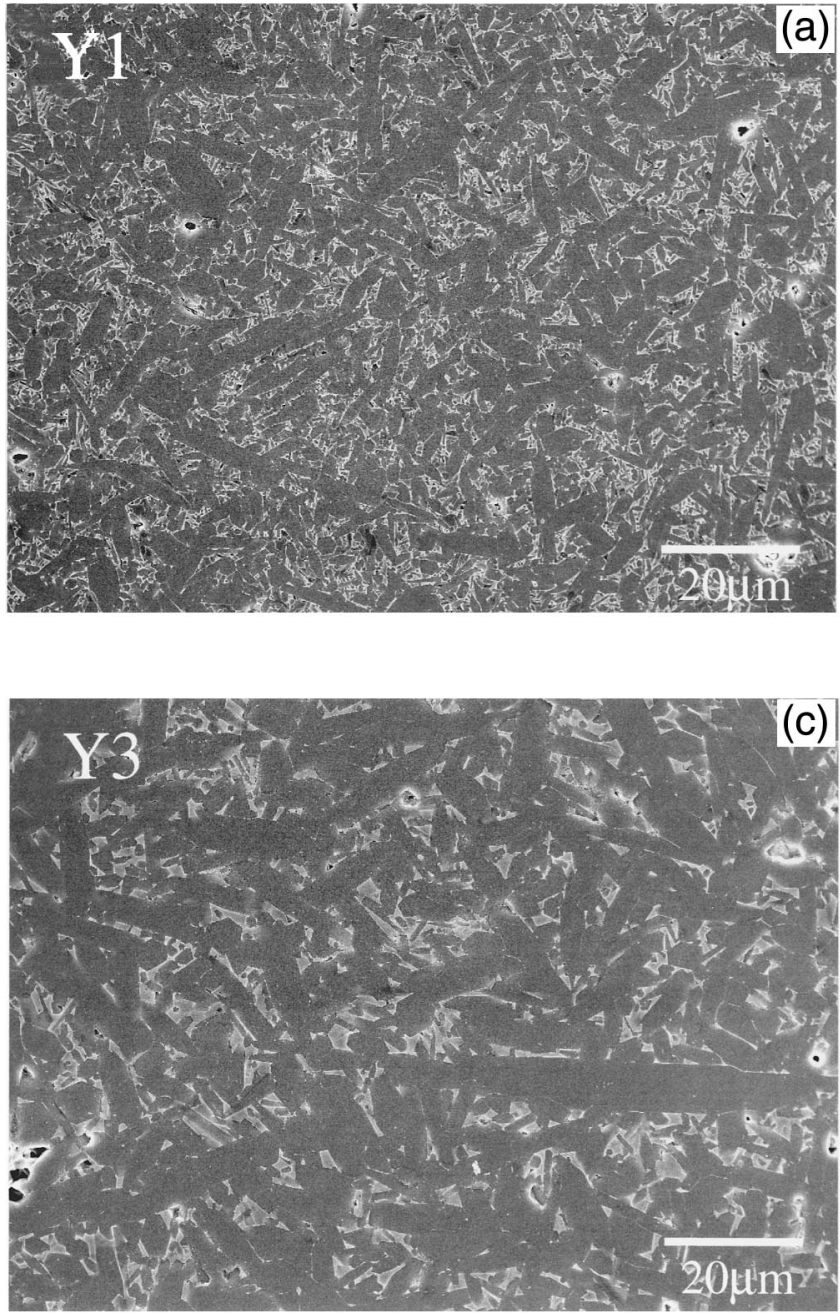

specimens, so that elongated $\beta$-grains have a tendency to lie along the plane of SEM observation. Evidently, the grain size increases as the $\mathrm{Y}_{2} \mathrm{O}_{3}: \mathrm{SiO}_{2}$ ratio increases from sample $\mathrm{Y} 1$ to sample $\mathrm{Y} 3$. However, the grain size changes only slightly from sample $\mathrm{Y} 3$ to sample Y4.

Table II summarizes the corrected $\mathrm{Y}_{2} \mathrm{O}_{3} / \mathrm{SiO}_{2}$ ratios, the grainboundary volume fraction calculated using the phase diagram shown in Fig. 2 (the density of each terminal compound was used for calculation), and the densities of the sintered bodies, as well as the grain sizes and thermal conductivities $(\kappa)$ of the para and perp specimens. The illustration shown in Fig. 1 indicates that it is easy to understand that the measured $\kappa$ values are the values perpendicular to the planes observed via SEM; hence, the mean grain sizes of the para and perp specimens correspond to the $\kappa$ values of the respective perp and para specimens. The differences in the mean grain size between the para and perp specimens are quite small, probably because of the method of determination. Because of the rodlike grain shape of $\beta-\mathrm{Si}_{3} \mathrm{~N}_{4}$, the linear-intercept method determines a mean grain size that is similar to the grain width. The $\kappa$ values of the para specimens are always smaller than those of the perp specimens, because of the alignment of the elongated $\beta$ $\mathrm{Si}_{3} \mathrm{~N}_{4}$ grains due to the hot pressing, as noted in the previous paper. ${ }^{1}$

Figure 4 shows the increase in the $\kappa$ value of $\beta-\mathrm{Si}_{3} \mathrm{~N}_{4}$, relative to the increase of the $\mathrm{Y}_{2} \mathrm{O}_{3} / \mathrm{SiO}_{2}$ ratio. A significant increase in $\kappa$ occurs at $\mathrm{Y}_{2} \mathrm{O}_{3} / \mathrm{SiO}_{2} \approx 1$. Below and above this critical ratio, the value of $\kappa$ does not change significantly. Figure 5 shows the relationship between the mean grain size and $\kappa$. Data from the previous work ${ }^{1}$ (5 wt $\% \quad \mathrm{Y}_{2} \mathrm{O}_{3}$ additive, grain-boundary volume fraction of $\sim 6 \%$ ) also are shown in this figure for comparison. The relationships between the mean grain size and $\kappa$ for samples $\mathrm{Y} 3$

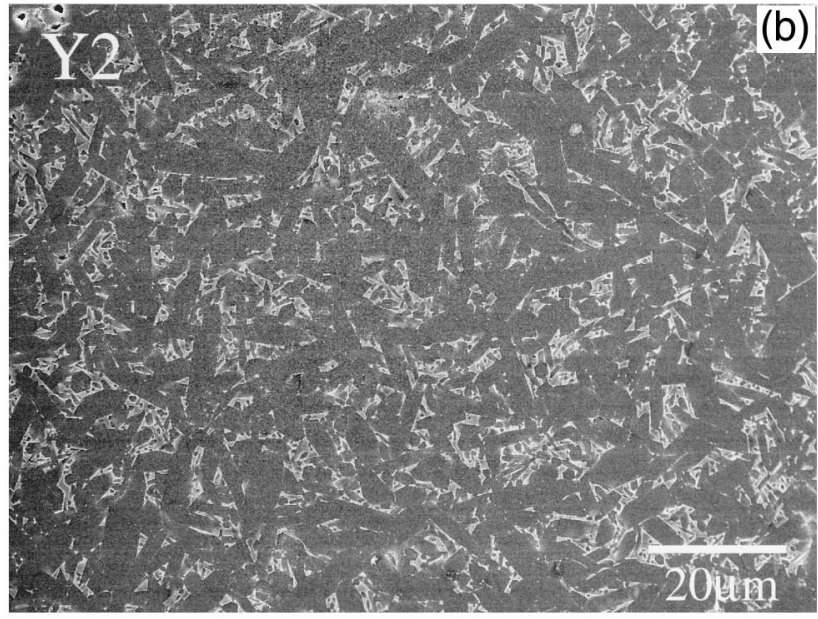

Fig. 3. SEM micrographs of polished and plasma-etched surfaces of samples Y1-Y4. All micrographs are from the "para" specimens. 
Table II. $\mathrm{Y}_{2} \mathrm{O}_{3} / \mathrm{SiO}_{2}$ Ratios, Grain-Boundary Volume Fractions, and Densities of Sintered Bodies, as Well as Grain Sizes and Thermal Conductivities of the "Para" and "Perp" Specimens for Samples Y1-Y4

\begin{tabular}{|c|c|c|c|c|c|c|c|}
\hline \multirow[b]{2}{*}{ Sample } & \multirow{2}{*}{$\underset{\text { ratio }^{+}}{\mathrm{Y}_{2} \mathrm{O}_{3} / \mathrm{SiO}_{2}}$} & \multirow{2}{*}{$\begin{array}{c}\text { Grain-boundary } \\
\text { volume fraction } \\
\quad(\text { vol } \%)\end{array}$} & \multirow{2}{*}{$\begin{array}{l}\text { Density } \\
\left(\mathrm{g} / \mathrm{cm}^{3}\right)\end{array}$} & \multicolumn{2}{|c|}{ Grain size $(\mu \mathrm{m})$} & \multicolumn{2}{|c|}{$\begin{array}{c}\text { Thermal conductivity } \\
\left(\mathrm{W} \cdot(\mathrm{m} \cdot \mathrm{K})^{-1}\right)\end{array}$} \\
\hline & & & & Para & Perp & Para & Perp \\
\hline Y1 & 0.289 & 10.11 & 3.211 & 1.98 & 1.73 & 50.1 & 58.8 \\
\hline Y2 & 0.807 & 8.02 & 3.240 & 2.64 & 2.45 & 56.0 & 68.6 \\
\hline Y3 & 1.267 & 8.81 & 3.290 & 4.17 & 3.96 & 79.1 & 100.4 \\
\hline Y4 & 2.029 & 12.33 & 3.327 & 4.32 & 4.17 & 75.9 & 99.1 \\
\hline
\end{tabular}

Corrected for the oxygen content of $\alpha-\mathrm{Si}_{3} \mathrm{~N}_{4}$ powder.

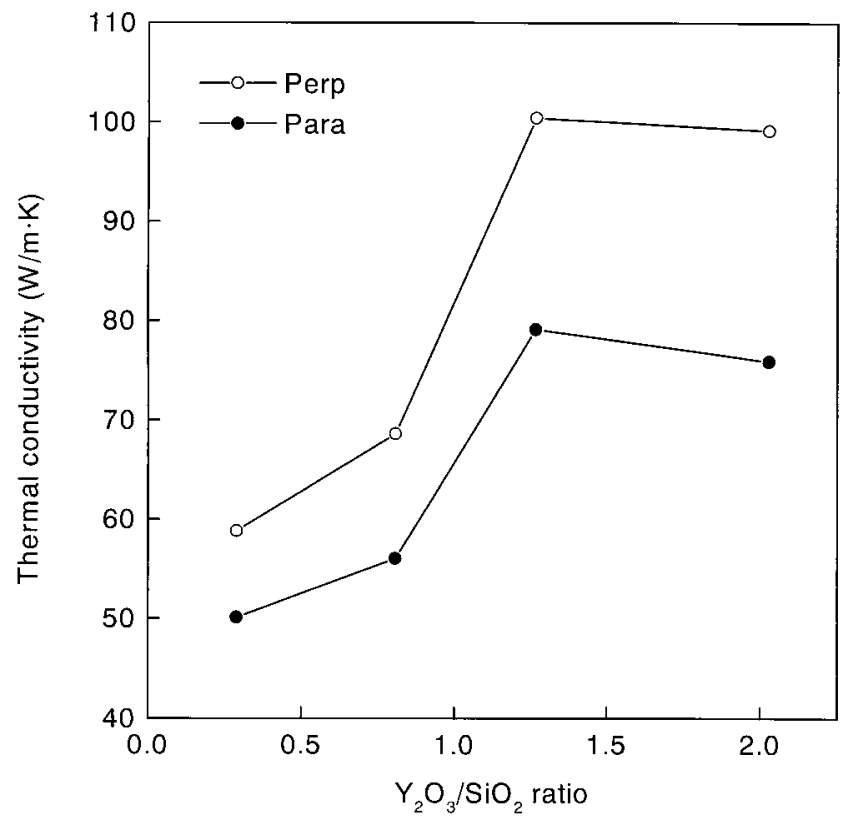

Fig. 4. Relationship between the $\mathrm{Y}_{2} \mathrm{O}_{3} / \mathrm{SiO}_{2}$ ratios and thermal conductivities of samples Y1-Y4.

and Y4 were very similar to those of the previous data. However, those of samples Y1 and Y2 show smaller values for similar mean grain sizes, which suggests that certain effects other than the grain size and the associated "average grain-boundary-film thickness"1 significantly decrease the $\kappa$ values of samples Y1 and Y2.

\section{(3) Hot-Gas Extraction}

In a previous paper, ${ }^{9}$ the lattice oxygen content of $\beta-\mathrm{Si}_{3} \mathrm{~N}_{4}$ crystals that had been heat-treated with a mixture of $\mathrm{Y}_{2} \mathrm{O}_{3}$ and $\mathrm{SiO}_{2}$ in a loose powder state was measured, following removal of the grain-boundary phase by acid treatments. Because the decomposition temperature of $\beta-\mathrm{Si}_{3} \mathrm{~N}_{4}$ was much lower $\left(\sim 1850^{\circ} \mathrm{C}\right)$ than that of AlN $\left(\sim 2000^{\circ} \mathrm{C}\right)$, the grain-boundary phase had to be removed before analysis. Otherwise, the oxygen release from the grain-boundary phase would almost mask that from the $\mathrm{Si}_{3} \mathrm{~N}_{4}$ crystal. Also, Gaussian peak separation was necessary to distinguish oxygen release from the decomposition of the residual secondary phase and the crystal lattice. ${ }^{9}$ These processes were not necessary for AlN. ${ }^{10}$ In this study, this method has been applied further to dense polycrystals.

Table III summarizes the lattice oxygen contents of samples Y1-Y4 and those of samples $\mathrm{Y} 1 *$ and $\mathrm{Y} 2 *$; the latter two samples are crystalline $\beta-\mathrm{Si}_{3} \mathrm{~N}_{4}$ powders that were obtained in the previous work ${ }^{9}$ by heat-treating the powder mixtures in a loose powder state at $1850^{\circ} \mathrm{C}$ for $2 \mathrm{~h}$, using the same additive ratios as samples $\mathrm{Y} 1$ and $\mathrm{Y} 2$ in this work, respectively. The lattice oxygen content evidently decreases significantly from sample $\mathrm{Y} 1$ to sample $\mathrm{Y} 3$ as the $\mathrm{Y}_{2} \mathrm{O}_{3} / \mathrm{SiO}_{2}$ ratio increases. However, the lattice oxygen content

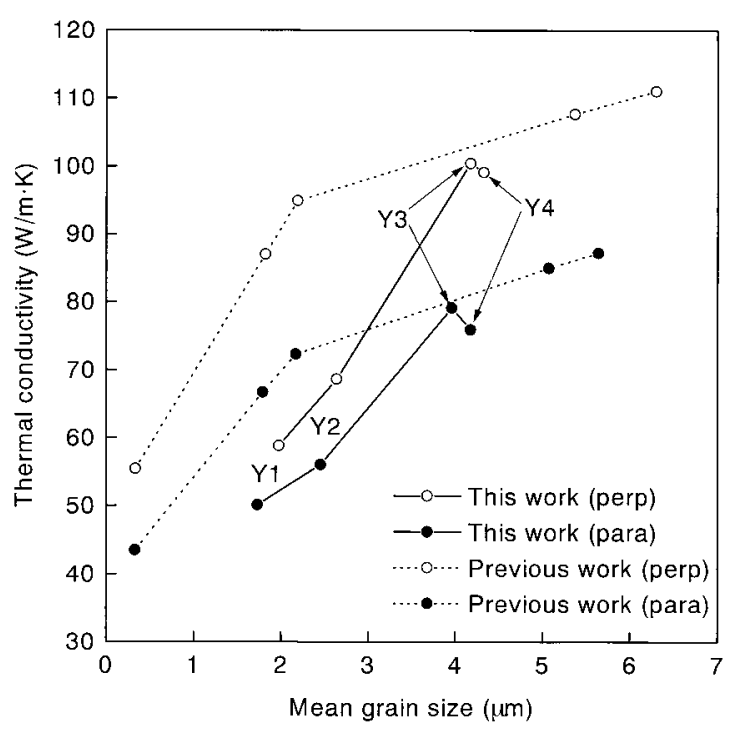

Fig. 5. Relationship between the mean grain sizes and thermal conductivities of samples $\mathrm{Y} 1-\mathrm{Y} 4$. Data from the previous work ${ }^{1}\left(5 \mathrm{wt} \% \mathrm{Y}_{2} \mathrm{O}_{3}\right.$ additive, grain-boundary volume fraction of $5 \%-6 \%$ ) also are shown for comparison.

Table III. $\quad \beta-\mathrm{Si}_{3} \mathrm{~N}_{4}$ Lattice Oxygen Contents Determined by Hot-Gas Extraction, and Spin Numbers per Unit Volume Determined via ESR for Samples Y1-Y4, Y1*, and Y2*

\begin{tabular}{ccc}
\hline Sample & $\begin{array}{c}\text { Lattice oxygen content } \\
(\text { wt } \%)\end{array}$ & $\begin{array}{c}\text { Spin number per volume } \\
\left(\times 10^{18} / \mathrm{cm}^{3}\right)\end{array}$ \\
\hline Y1 & $0.400 \pm 0.001$ & 1.13 \\
Y2 & $0.185 \pm 0.014$ & 1.63 \\
Y3 & $0.064 \pm 0.004$ & 3.44 \\
Y4 & $0.058 \pm 0.001$ & 4.82 \\
Y1* & $0.258 \pm 0.006$ & 1.03 \\
$Y^{*} *$ & $0.158 \pm 0.003$ & 2.64 \\
\hline
\end{tabular}

changes only slightly from sample $\mathrm{Y} 3$ to sample $\mathrm{Y} 4$ with further increases in the $\mathrm{Y}_{2} \mathrm{O}_{3} / \mathrm{SiO}_{2}$ ratio.

Although the $\mathrm{Y}_{2} \mathrm{O}_{3} / \mathrm{SiO}_{2}$ additive ratios of samples $\mathrm{Y} 1$ and $\mathrm{Y} 2$ are the same as those of samples $\mathrm{Y} 1^{*}$ and $\mathrm{Y} 2^{*}$, the lattice oxygen contents of the former samples are much larger than those of the latter samples. This disparity is probably due to differences in the amount of total $\mathrm{SiO}_{2}$, which is caused by the use of different amounts of $\mathrm{Si}_{3} \mathrm{~N}_{4}$ raw powder (samples $\mathrm{Y} 1$ and $\mathrm{Y} 2$ have twice as much $\mathrm{Si}_{3} \mathrm{~N}_{4}$ as samples $\mathrm{Y}^{*}$ and $\mathrm{Y}^{*}$ ). Also, the heat-treatment conditions (hot pressing for the former samples and a loose powder state for the latter samples) will lead to differences in the amount of $\mathrm{SiO}_{2}$, because of vaporization.

As mentioned elsewhere, ${ }^{9}$ the peak for oxygen release coincides with that for nitrogen release, because of the decomposition of the $\beta-\mathrm{Si}_{3} \mathrm{~N}_{4}$ crystal. Thus, we judged that it be the oxygen dissolved in the $\beta-\mathrm{Si}_{3} \mathrm{~N}_{4}$ crystal lattice. To confirm that the oxygen amounts 
shown in Table III do, in fact, dissolve in the $\beta-\mathrm{Si}_{3} \mathrm{~N}_{4}$ crystal lattice, additional ESR analyses were performed.

\section{(4) ESR Analyses}

Figure 6 shows the ESR spectra of samples Y1-Y4. The specimen volumes were not constant; therefore, ESR spectra were normalized by their volumes. The $g$-value was determined to be 2.0028 , by comparison with that of DPPH. This value agrees with that measured for stoichiometric amorphous $\mathrm{Si}_{3} \mathrm{~N}_{4}$ that was made via the thermal nitridation of silicon metal and is characterized as a dangling bond on a $\mathrm{Si}$ atom back-bonded to three $\mathrm{N}$ atoms $\left(\cdot \mathrm{Si} \equiv \mathrm{N}_{3}\right)$; this location is called the K-center. ${ }^{12}$ It is identical to the nitrogen vacancy $V_{\mathrm{N}}^{\cdots}$ in the $\beta-\mathrm{Si}_{3} \mathrm{~N}_{4}$ crystal lattice. Table III also gives the numbers of spins per unit volume of samples $\mathrm{Y} 1-\mathrm{Y} 4$, as well as those of samples $\mathrm{Y} 1 *$ and $\mathrm{Y} 2 *$, as determined using double integration of the derivative absorption signals that are shown in Fig. 6. Good correlation was observed between the number of spins per unit volume and the thermal conductivities of samples $\mathrm{Y} 1-\mathrm{Y} 4$, as observed for AlN ceramics. ${ }^{11}$

\section{Discussion}

\section{(1) Relationship between the Number of Spins Determined by ESR and the Oxygen Contents}

The relationship between the concentrations of lattice oxygens and nitrogen vacancies has been reported for AlN, ${ }^{11}$ and the same discussion can be made for $\mathrm{Si}_{3} \mathrm{~N}_{4}$. When $\mathrm{O}$ atoms are incorporated into the $\mathrm{Si}_{3} \mathrm{~N}_{4}$ crystal lattice and substitute onto a portion of the $\mathrm{N}$ sites, it produces a Si vacancy $\left(V_{\mathrm{Si}}^{\prime \prime \prime}\right)$ :

$$
2 \mathrm{O}_{2} \rightarrow 4 \mathrm{O}_{\mathrm{N}}^{\cdot}+V_{\mathrm{Si}}^{\prime \prime \prime}
$$

Thus,

$$
K_{1}=\frac{\left[\mathrm{O}_{\mathrm{N}}\right]^{4}\left[V_{\mathrm{Si}}^{\prime \prime \prime}\right]}{\left(P_{\mathrm{O}_{2}}\right)^{2}}
$$

where $P_{\mathrm{O}_{2}}$ is the partial pressure of oxygen. The electroneutrality condition requires

$$
\left[V_{\mathrm{Si}}^{\prime \prime \prime}\right]=\frac{1}{4}\left[\mathrm{O}_{\mathrm{N}}\right]
$$

In the $\mathrm{Si}_{3} \mathrm{~N}_{4}$ crystal lattice, silicon and nitrogen vacancies are

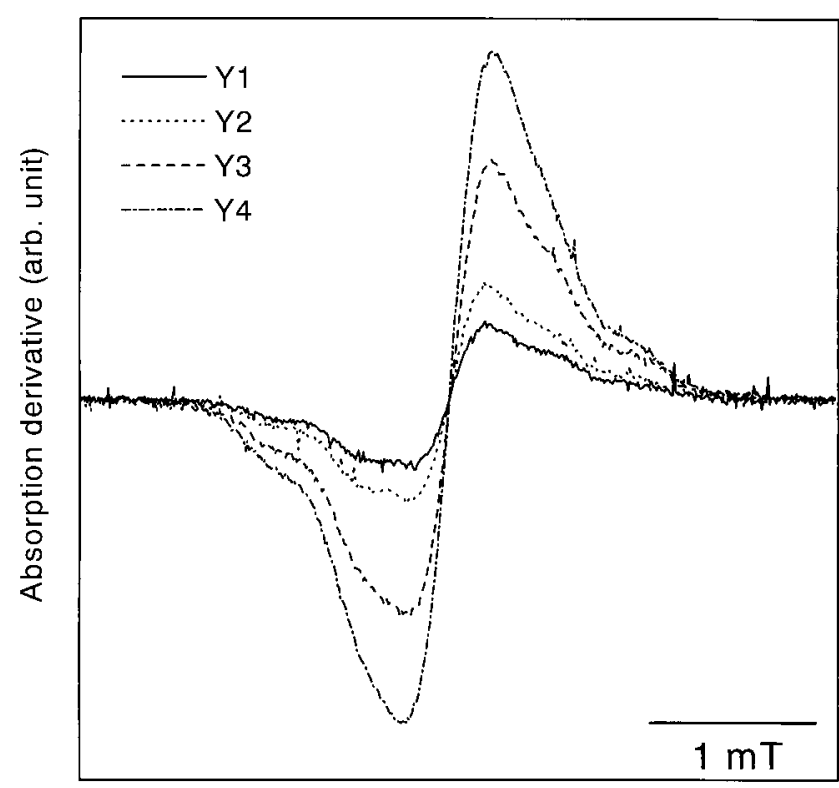

Magnetic field $\rightarrow$

Fig. 6. Normalized ESR derivative absorption spectra of samples Y1-Y4.

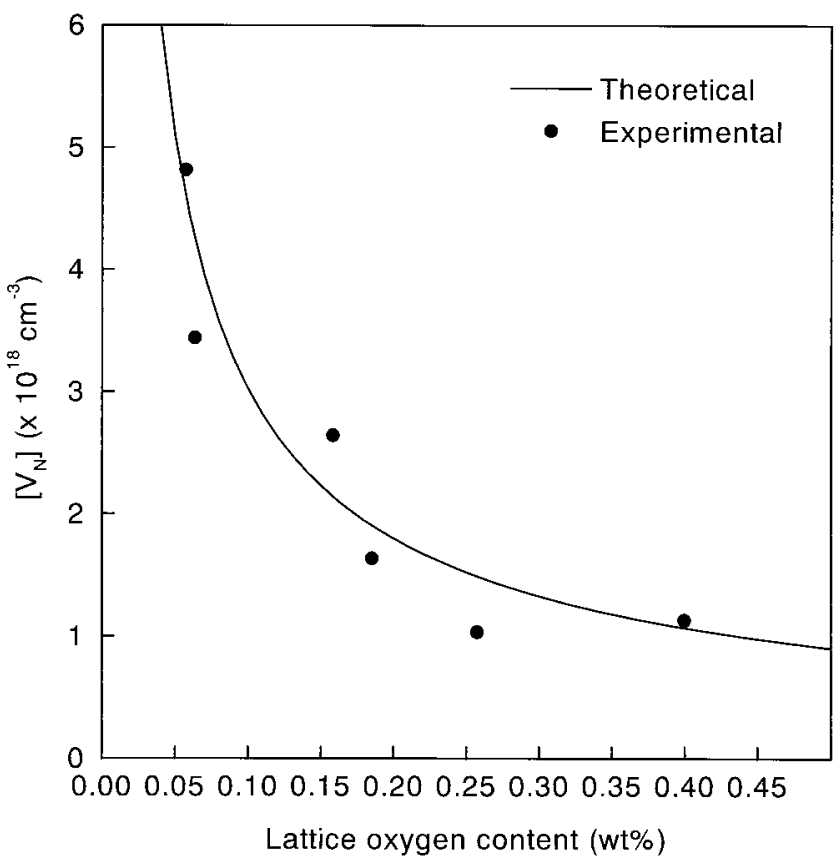

Fig. 7. Comparison of experimental and theoretical relationships between the lattice oxygen content and the nitrogen vacancy concentration.

produced under thermal equilibrium:

$$
\text { null } \rightarrow 3\left[V_{\mathrm{Si}}^{\prime \prime \prime}\right]+4\left[V_{\mathrm{N}}^{\cdots \cdot}\right]
$$

Thus,

$$
K_{2}=\left[V_{\mathrm{Si}}^{\prime \prime \prime \prime}\right]^{3}\left[V_{\mathrm{N}}^{\cdots}\right]^{4}
$$

Combining Eqs. (3) and (5), the relationship between nitrogen vacancies and the oxygen concentration is expressed by the following equation:

$$
\left[V_{\mathrm{N}}^{\cdots}\right]=\left\{\frac{K_{2}}{\left(\frac{1}{4}\left[\mathrm{O}_{\mathrm{N}}^{\cdot}\right]\right)^{3}}\right\}^{1 / 4}
$$

This equation indicates that the concentration of nitrogen vacancies increases as the oxygen concentration decreases.

Each silicon vacancy $V_{\mathrm{Si}}^{\prime \prime \prime \prime}$ in the $\mathrm{Si}_{3} \mathrm{~N}_{4}$ lattice is surrounded by four $\mathrm{N}$ atoms with a dangling bond, which can readily make two local $\mathrm{N}-\mathrm{N}$ bonds. Thus, $V_{\mathrm{Si}}^{\prime \prime \prime \prime}$ is not expected to be an ESR-active vacancy. In contrast, each nitrogen vacancy in the $\mathrm{Si}_{3} \mathrm{~N}_{4}$ lattice $\left(V_{\mathrm{N}}^{*}\right)$ is surrounded by three $\mathrm{Si}$ atoms with a dangling bond (the $\mathrm{K}$-center). Two of these atoms can make one local $\mathrm{Si}-\mathrm{Si}$ bond, but one dangling bond still remains; thus, $V_{\mathrm{N}}^{\cdots}$ is expected to be an ESR-active vacancy. This hypothesis is plausible for the following reasons: (i) the $g$-value determined in this work agrees quite well with the known $g$-value for the K-center, ${ }^{12}$ and (ii) simulations that assumed hyperfine interaction between the electron spin and nucleus spins of three $\mathrm{N}$ atoms back-bonded to $\mathrm{Si}$ (C3 symmetry)

Table IV. Estimated Thermal Conductivity of Crystalline

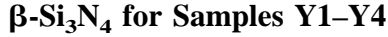

\begin{tabular}{ccc}
\hline Sample & $\begin{array}{c}\text { Average } \\
\text { grain-boundary film } \\
\text { thickness, } \bar{\delta}^{\dagger}(\mathrm{nm})\end{array}$ & $\begin{array}{c}\text { Thermal conductivity of the } \\
\mathrm{S}^{*} \mathrm{~N}_{3} \mathrm{crystal}^{*}\left(\mathrm{~W} \cdot(\mathrm{m} \cdot \mathrm{K})^{-1}\right)\end{array}$ \\
\hline Y1 & 15 & 100 \\
Y2 & 19 & 115 \\
Y3 & 27 & 185 \\
Y4 & 28 & 190 \\
\hline
\end{tabular}

${ }^{\dagger}$ Values estimated from mean grain sizes obtained via comparison with the previous data. ${ }^{*}$ *Values estimated from calculations based on the modified Wiener model. 

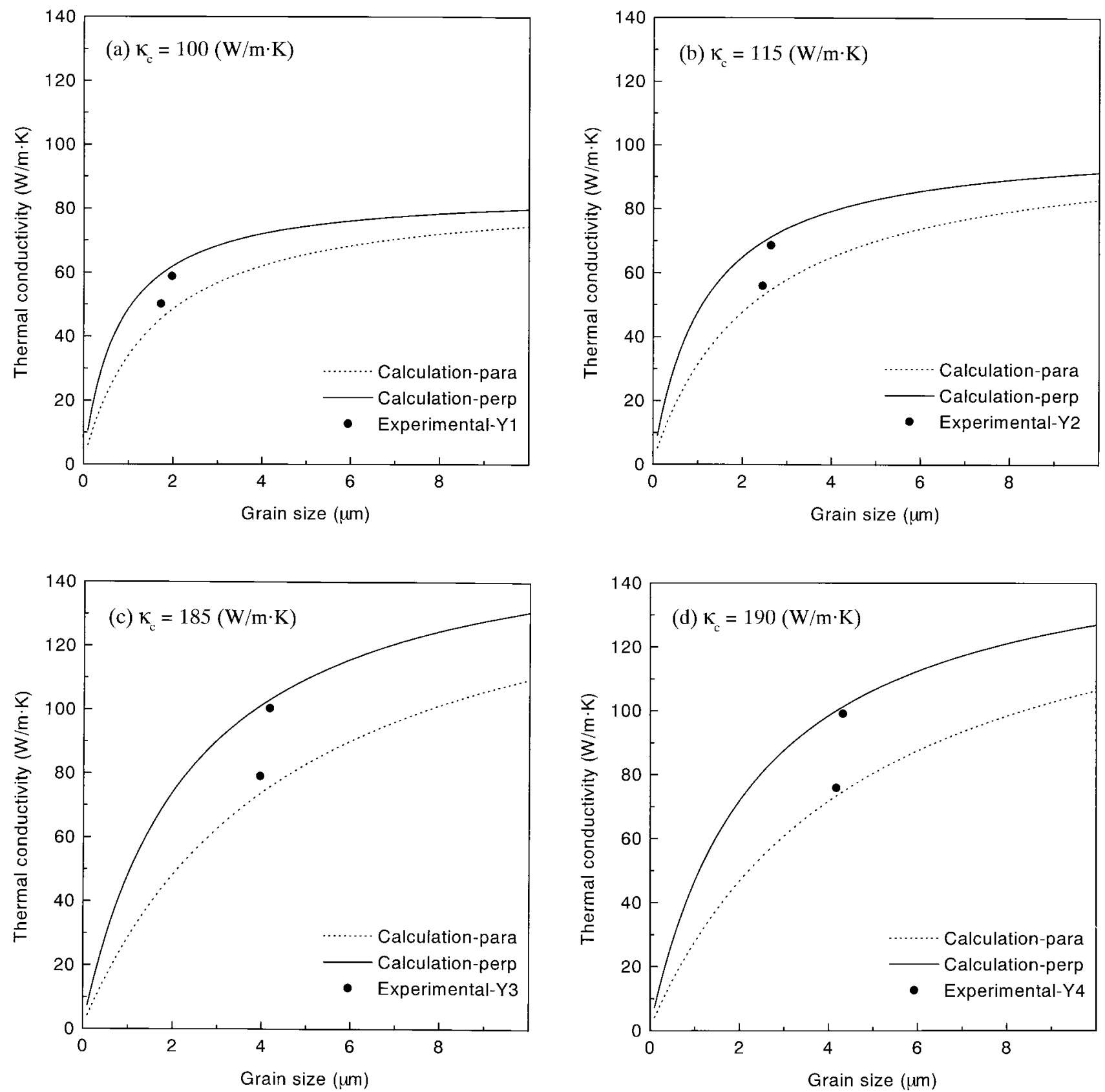

Fig. 8. Comparison of the grain-size/thermal-conductivity relationship between calculations (solid and dotted lines) and experimental data (data points). Calculations are performed using "average grain-boundary-film thicknesses" and thermal conductivities of crystalline $\beta-\mathrm{Si}_{3} \mathrm{~N}_{4}$ ( $\kappa_{\mathrm{c}}$ ) of (a) $15 \mathrm{~nm}$ and 100 $\mathrm{W} \cdot(\mathrm{m} \cdot \mathrm{K})^{-1}$, (b) $19 \mathrm{~nm}$ and $115 \mathrm{~W} \cdot(\mathrm{m} \cdot \mathrm{K})^{-1}$, (c) $27 \mathrm{~nm}$ and $185 \mathrm{~W} \cdot(\mathrm{m} \cdot \mathrm{K})^{-1}$, and (d) $28 \mathrm{~nm}$ and $190 \mathrm{~W} \cdot(\mathrm{m} \cdot \mathrm{K})^{-1}$ for samples $\mathrm{Y} 1$, Y2, Y3, and Y4, respectively.

successfully produced ESR spectra that were very similar to those observed for samples $\mathrm{Y} 1-\mathrm{Y} 4 .{ }^{13}$ If two or more electron spins exist, resultant ESR spectra become much-more complicated than those shown in Fig. 6. Thus, if $V_{\mathrm{N}}^{\cdots}$ is the only source of electron spins that are detected via ESR, the number of spins per unit volume is equal to $\left[V_{\mathrm{N}}^{\cdots}\right]$. Equation (6) indicates that the product $\left(1 / 4\left[\mathrm{O}_{\mathrm{N}}^{*}\right)^{3} \times\right.$ $\left[V_{\mathrm{N}}^{\cdots}\right]^{4}$ should be constant. The $\left(1 / 4\left[\mathrm{O}_{\mathrm{N}}^{-}\right]\right)^{3} \times\left[V_{\mathrm{N}}^{\cdots}\right]^{4}$ products are calculated from measured oxygen contents (determined via hot-gas extraction) and the numbers of spins (determined via ESR), and then the products are averaged. Using this value $\left(K_{2}\right)$, a theoretical relationship between the concentrations of lattice oxygen atoms and nitrogen vacancies (equal to the number of spins per unit volume) is determined, according to Eq. (6). Figure 7 compares the theoretical relationship with the experimental data given in Table III. The experimentally determined relationship between the concentrations of lattice oxygen atoms and nitrogen vacancies agrees quite well with that determined theoretically from Eq. (6), which indicates the validity of the above-mentioned assumptions and further suggests that oxygen, in fact, dissolves in the $\beta-\mathrm{Si}_{3} \mathrm{~N}_{4}$ crystal lattice. This work has shown the possibility that the ESR analysis quantifies the lattice oxygen content, using Eq. (6).

\section{(2) Estimated Thermal Conductivity of the $\mathrm{\beta}-\mathrm{Si}_{3} \mathrm{~N}_{4}$ Crystal}

As reported elsewhere, ${ }^{14}$ the $\mathrm{Y}_{2} \mathrm{O}_{3} / \mathrm{SiO}_{2}$ additive ratio has a significant effect on the grain-growth behavior of $\beta-\mathrm{Si}_{3} \mathrm{~N}_{4}$. In this study, grain size has been confirmed to increase as the $\mathrm{Y}_{2} \mathrm{O}_{3} / \mathrm{SiO}_{2}$ additive ratio increases. According to previous work, ${ }^{1} \mathrm{~K}$ increases steeply up to a certain critical grain size. In addition, a new concept of the average grain-boundary-film thickness was introduced. Although a portion of the grain boundary has an "equilibrium film thickness" of $\sim 1 \mathrm{~nm},{ }^{15}$ a majority of the grain-boundary phase has a tendency to have a filmlike morphology with a much-larger thickness than the equilibrium film thickness, because of the faceting nature of crystalline $\beta-\mathrm{Si}_{3} \mathrm{~N}_{4}$. We have defined it as a 
"thick film." Because of the filmlike morphology, the grainboundary phase significantly reduces the $\kappa$ value of the $\beta-\mathrm{Si}_{3} \mathrm{~N}_{4}$ sintered body. The average grain-boundary-film thickness also has been demonstrated to increase as the grain size increases. Thus, the thermal conductivity ( $\kappa$ ) of the $\beta-\mathrm{Si}_{3} \mathrm{~N}_{4}$ sintered body was expressed as a function of the average grain size $\bar{d}$, the average grain-boundary-film thickness $\bar{\delta}$, shape factors $F_{\mathrm{s}}$ (aspect ratio and alignment), and lattice defects $D_{1}$ :

$$
\kappa=f\left(\bar{d}, \bar{\delta}, F_{\mathrm{s}}, D_{1}\right)
$$

Here, we want to estimate the $\kappa$ value of the $\beta-\mathrm{Si}_{3} \mathrm{~N}_{4}$ crystal itself and elucidate the effect of lattice defects $\left(\kappa=f\left(D_{1}\right)\right)$ by excluding the microstructural effects of the $\bar{d}, \bar{\delta}$, and $F_{\mathrm{s}}$ terms. The value of $\bar{\delta}$ is calculated from the mean grain sizes of samples Y1-Y4, using the relationship of grain size versus average grain-boundary-film thickness that was obtained in the previous work. ${ }^{1}$ The mean aspect ratio is assumed to be equal to 2 , and the $\kappa$ value of the grain-boundary phase is assumed to be $1 \mathrm{~W} \cdot(\mathrm{m} \cdot \mathrm{K})^{-1}$. Several calculations based on the modified Wiener's model ${ }^{1}$ were performed using various $\kappa$ values of crystalline $\beta-\mathrm{Si}_{3} \mathrm{~N}_{4}$. The $\kappa$ values of crystalline $\beta-\mathrm{Si}_{3} \mathrm{~N}_{4}$ yielded the most-similar grain-size/thermalconductivity relationships for each sample; these values are summarized in Table IV. Figures 8(a), (b), (c), and (d) compare the results of calculations and experimental data for samples Y1, Y2, Y3, and Y4, respectively. Good agreement between the values was observed in each case.

The lattice-defects term $D_{1}$ is a sum of point defects, line defects (dislocations), and stacking faults. A significant density of dislocations $\left(\sim 10^{9} / \mathrm{cm}^{2}\right)$ was observed for $\beta-\mathrm{Si}_{3} \mathrm{~N}_{4}$ on crystallization of the grain-boundary phase. ${ }^{16}$ However, point defects generally are accepted to have a dominant effect on $\kappa$ for inorganic crystalline materials that transfer heat predominantly via phonons. ${ }^{3}$ Figure 9 shows the relationship between the lattice oxygen content and the estimated thermal resistivity $(1 / \kappa)$ of crystalline $\beta-\mathrm{Si}_{3} \mathrm{~N}_{4}$ shown in Table IV. For AlN single crystals, a linear relationship has been proposed, ${ }^{3,4}$ which is given by the line in Fig. 9. A positive correlation also is observed for crystalline $\beta-\mathrm{Si}_{3} \mathrm{~N}_{4}$. Although some deviations would exist between the true and estimated values, this trend would be unchanged.

Consequently, we conclude that the point defects in the $\beta-\mathrm{Si}_{3} \mathrm{~N}_{4}$ crystal lattice that are created by oxygen dissolution dictate the thermal conductivity of this material, similar to the case in AlN

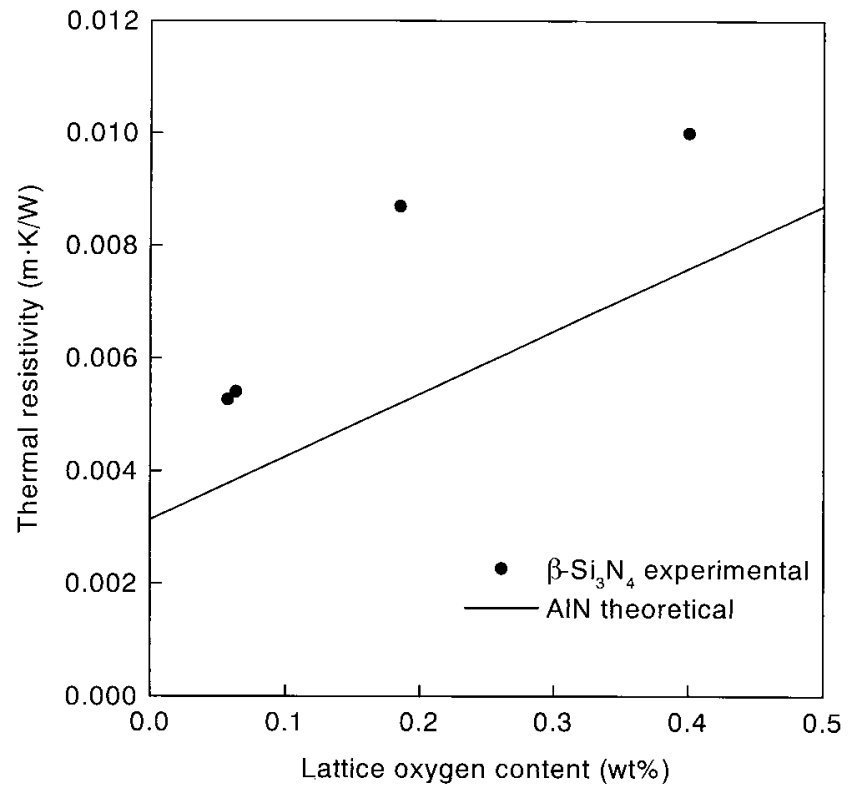

Fig. 9. Relationship between the lattice oxygen contents determined by the hot-gas extraction method and thermal resistivities (inverse of thermal conductivities) of $\beta-\mathrm{Si}_{3} \mathrm{~N}_{4}$ crystal estimated from calculations shown in Fig. 8. Line represents the theoretical correlation for single-crystal AlN. ceramics. The correlation between the lattice oxygen content and the thermal resistivity of crystalline $\beta-\mathrm{Si}_{3} \mathrm{~N}_{4}$ is not a straight line, as was proposed for AlN single crystals. This nonlinear relation may be due to the more-complicated structure of the $\beta-\mathrm{Si}_{3} \mathrm{~N}_{4}$ crystal than that of the AlN crystal, which is categorized as a simple adamantine compound.

\section{(3) Effect of the Grain-Boundary Phase on the Lattice Oxygen Content}

Following thermodynamic arguments that were made by Jackson et al. ${ }^{7}$ to explain the effect of the grain-boundary phase composition on the $\kappa$ value of $\mathrm{Y}_{2} \mathrm{O}_{3}$-doped AlN ceramics, a corresponding standard free-energy diagram, as a function of the $\mathrm{Y}_{2} \mathrm{O}_{3} / \mathrm{SiO}_{2}$ ratio of the grain-boundary phase, is shown in Fig. 10. The activity of $\mathrm{SiO}_{2}\left(a_{\mathrm{SiO}_{2}}\right)$ in the three-phase fields may be related solely to the $\mathrm{Y}_{2} \mathrm{O}_{3} / \mathrm{SiO}_{2}$ ratio, because the activity of $\mathrm{Si}_{3} \mathrm{~N}_{4}$ is always unity. The liquid phase at the annealing temperature was assumed to be in equilibrium with the phases observed via XRD. For sample Y1, the value of $a_{\mathrm{SiO}_{2}}$ is determined by the $\mathrm{Si}_{2} \mathrm{~N}_{2} \mathrm{O}$ $\mathrm{Y}_{2} \mathrm{Si}_{2} \mathrm{O}_{7}$ tie line and is equal to that of the $\mathrm{Si}_{3} \mathrm{~N}_{4}-\mathrm{Si}_{2} \mathrm{~N}_{2} \mathrm{O}$ system. Thus, the activity in this sample is the highest of all the samples. For sample $\mathrm{Y} 2$, the value of $a_{\mathrm{SiO}_{2}}$ is determined by the $\mathrm{Y}_{2} \mathrm{Si}_{2} \mathrm{O}_{7}-$ $\mathrm{Y}_{20} \mathrm{~N}_{4} \mathrm{Si}_{12} \mathrm{O}_{48}$ tie line and is smaller than that of sample $\mathrm{Y} 1$. For sample Y4, the value of $a_{\mathrm{SiO}_{2}}$ is determined by the $\mathrm{Y}_{20} \mathrm{~N}_{4} \mathrm{Si}_{12} \mathrm{O}_{48}-$ $\mathrm{Y}_{2} \mathrm{Si}_{3} \mathrm{~N}_{4} \mathrm{O}_{3}$ tie line and is the smallest value among all the samples. The activity of $\mathrm{SiO}_{2}$ of the grain-boundary phase should affect the oxygen solubility in the $\beta-\mathrm{Si}_{3} \mathrm{~N}_{4}$ crystal lattice of sintered bodies, which explains the change of lattice oxygen atoms due to the $\mathrm{Y}_{2} \mathrm{O}_{3} / \mathrm{SiO}_{2}$ ratio in this work. Although only $\mathrm{Y}_{20} \mathrm{~N}_{4} \mathrm{Si}_{12} \mathrm{O}_{48}$ was observed for sample $\mathrm{Y} 3$, it probably contains a small amount of $\mathrm{Y}_{2} \mathrm{Si}_{3} \mathrm{~N}_{4} \mathrm{O}_{3}$ phase, considering that the oxygen content and $\kappa$ value of sample Y3 were almost identical to that of sample Y4. Because the melting points, viscosities, and wetting behaviors would differ for different phases, and their different effects indeed affect the oxygen removal during sintering, the total change of these properties due to various $\mathrm{Y}_{2} \mathrm{O}_{3} / \mathrm{SiO}_{2}$ ratios would control the value of $\kappa$ for $\beta-\mathrm{Si}_{3} \mathrm{~N}_{4}$.

The experimental results strongly suggest that both the $\mathrm{Y}_{20} \mathrm{~N}_{4} \mathrm{Si}_{12} \mathrm{O}_{48}$ and $\mathrm{Y}_{2} \mathrm{Si}_{3} \mathrm{~N}_{4} \mathrm{O}_{3}$ phases should be present in the grain-boundary phase of $\beta-\mathrm{Si}_{3} \mathrm{~N}_{4}$ ceramics that have been sintered with $\mathrm{Y}_{2} \mathrm{O}_{3}$ to guarantee high $\kappa$ values. However, greater $\mathrm{Y}_{2} \mathrm{O}_{3}$ addition than that in sample $\mathrm{Y} 3$ does not improve $\kappa$, as demonstrated experimentally; it significantly increases the amount of the grain-boundary phase, because of the formation of the $\mathrm{Y}_{2} \mathrm{Si}_{3} \mathrm{~N}_{4} \mathrm{O}_{3}$

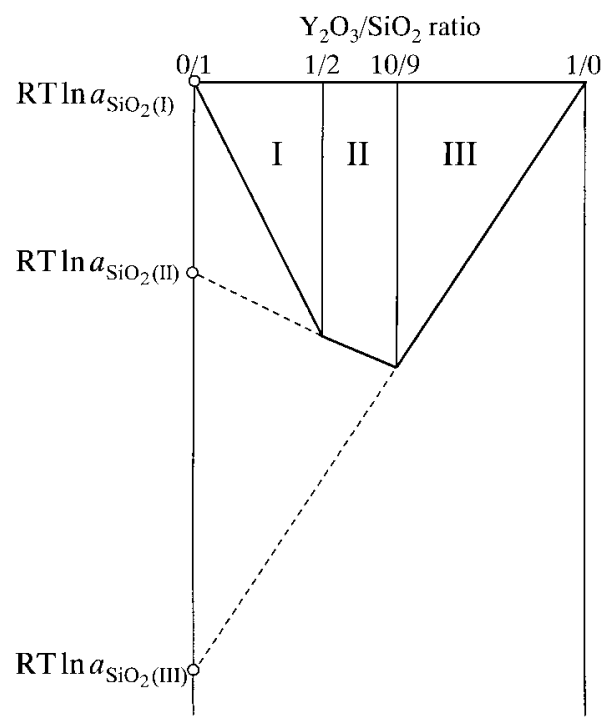

Fig. 10. Schematic standard free-energy diagram, as a function of the $\mathrm{Y}_{2} \mathrm{O}_{3} / \mathrm{SiO}_{2}$ ratio of the grain-boundary phase. Extrapolations of tie lines to $\mathrm{Y}_{2} \mathrm{O}_{3} / \mathrm{SiO}_{2}=0$ represent $R T \ln a_{\mathrm{SiO}_{2}}$ values. 
phase, without changing the value of $a_{\mathrm{SiO}_{2}}$, as shown in Fig. 10. Consequently, it is concluded that an optimum amount for $\mathrm{Y}_{2} \mathrm{O}_{3}$ addition exists, depending on the amount of oxygen impurities in the $\mathrm{Si}_{3} \mathrm{~N}_{4}$ raw powder, to achieve the highest $\kappa$ value in $\beta-\mathrm{Si}_{3} \mathrm{~N}_{4}$.

\section{Conclusions}

Two methods that were developed to analyze the lattice oxygen content and associated lattice defects in AlN-hot-gas extraction and electron spin resonance- have been shown to be applicable to $\beta-\mathrm{Si}_{3} \mathrm{~N}_{4}$. The thermal conductivity ( $\kappa$ ) and lattice oxygen content have been evaluated for $\beta-\mathrm{Si}_{3} \mathrm{~N}_{4}$ that has been sintered at various $\mathrm{Y}_{2} \mathrm{O}_{3} / \mathrm{SiO}_{2}$ additive ratios. The following conclusions can be determined, based on the current work:

(1) The $\kappa$ value for $\beta-\mathrm{Si}_{3} \mathrm{~N}_{4}$ increases as the $\mathrm{Y}_{2} \mathrm{O}_{3} / \mathrm{SiO}_{2}$ additive ratio increases. A significant increase in $\kappa$ occurs near the $\mathrm{Y}_{2} \mathrm{O}_{3} / \mathrm{SiO}_{2}=1$ grain-boundary phase composition.

(2) Grain size also increases as the $\mathrm{Y}_{2} \mathrm{O}_{3} / \mathrm{SiO}_{2}$ additive ratio increases.

(3) The lattice oxygen content decreases as the $\mathrm{Y}_{2} \mathrm{O}_{3} / \mathrm{SiO}_{2}$ additive ratio increases and attains a constant value if the grainboundary phase composition of $\mathrm{Y}_{2} \mathrm{O}_{3} / \mathrm{SiO}_{2} \approx 1$ is exceeded.

(4) To compare the $\kappa$ value of $\beta-\mathrm{Si}_{3} \mathrm{~N}_{4}$ crystals by excluding the microstructural effects, calculations were performed based on the model that was proposed in the previous work. ${ }^{1}$ A positive correlation between the lattice oxygen contents and estimated thermal resistivities of $\beta-\mathrm{Si}_{3} \mathrm{~N}_{4}$ crystal was observed, as was demonstrated for single-crystal AlN.

(5) The grain-boundary phase composition dictates the lattice oxygen content of $\beta-\mathrm{Si}_{3} \mathrm{~N}_{4}$. The lattice oxygen content is lowest when both $\mathrm{Y}_{20} \mathrm{~N}_{4} \mathrm{Si}_{12} \mathrm{O}_{48}$ and $\mathrm{Y}_{2} \mathrm{Si}_{3} \mathrm{~N}_{4} \mathrm{O}_{3}$ are present in the grain-boundary phase. Excess $\mathrm{Y}_{2} \mathrm{O}_{3}$ addition results in an increase of the grain-boundary phase without decreasing the lattice oxygen content. Thus, it is concluded that an optimum amount of $\mathrm{Y}_{2} \mathrm{O}_{3}$ addition exists, depending on the amount of oxygen impurities in the $\mathrm{Si}_{3} \mathrm{~N}_{4}$ raw powder, to achieve the highest $\kappa$ value in $\beta-\mathrm{Si}_{3} \mathrm{~N}_{4}$.

Collectively, the relationship between the microstructure, grainboundary phase, lattice oxygen content, and $\kappa$ value of $\beta-\mathrm{Si}_{3} \mathrm{~N}_{4}$ that has been sintered at various $\mathrm{Y}_{2} \mathrm{O}_{3} / \mathrm{SiO}_{2}$ additive ratios has been clarified in this work.

\section{Acknowledgments}

The authors deeply thank Dr. M. Okazaki (NIRIN) for his kind measurements of ESR spectra and helpful discussions. The authors also greatly appreciate simulations of ESR spectra that were performed by Dr. K. Toriyama (NIRIN).

\section{References}

${ }^{1}$ M. Kitayama, K. Hirao, M. Toriyama, and S. Kanzaki, "Thermal Conductivity of $\beta-\mathrm{Si}_{3} \mathrm{~N}_{4}$ : I, Effects of Various Microstructural Factors," J. Am. Ceram. Soc., 82 [11] 3105-12 (1999).

${ }^{2}$ K. Watari, K. Hirao, M. Toriyama, and K. Ishizaki, "Effect of Grain Size on the Thermal Conductivity of $\mathrm{Si}_{3} \mathrm{~N}_{4}$," J. Am. Ceram. Soc., 82 [3] 777-79 (1999).

${ }^{3}$ G. A. Slack, "Nonmetallic Crystals with High Thermal Conductivity," J. Phys. Chem. Solids, 34, 321-35 (1973).

${ }^{4}$ G. A. Slack, R. A. Tanzilli, R. O. Pohl, and J. W. Vandersande, "The Intrinsic Thermal Conductivity of AlN," J. Phys. Chem. Solids, 48 [7] 641-47 (1987).

${ }^{5}$ A. V. Virkar, T. B. Jackson, and R. A. Cutler, "Thermodynamic and Kinetic Effects of Oxygen Removal on the Thermal Conductivity of Aluminum Nitride," J. Am. Ceram. Soc., 72 [11] 2031-42 (1989).

${ }^{6}$ H. Buhr, G. Müller, H. Wiggers, F. Aldinger, P. Foley, and A. Roosen, "Phase Composition, Oxygen Content, and Thermal Conductivity of $\mathrm{AlN}\left(\mathrm{Y}_{2} \mathrm{O}_{3}\right)$ Ceramics," J. Am. Ceram. Soc., 74 [4] 718-23 (1991).

${ }^{7}$ T. B. Jackson, A. V. Virkar, K. L. More, R. B. Dinwiddie Jr., and R. A. Cutler, "High-Thermal-Conductivity Aluminum Nitride Ceramics: The Effect of Thermodynamic, Kinetic, and Microstructural Factors," J. Am. Ceram. Soc., 80 [6] 1421-35 (1997).

${ }^{8}$ C.-M. Wang, X. Pan, M. Rühle, F. L. Riley, and M. Mitomo, "Review: Silicon Nitride Crystal Structure and Observations of Lattice Defects," J. Mater. Sci., 31, 5281-98 (1996).

${ }^{9}$ M. Kitayama, K. Hirao, M. Toriyama, and S. Kanzaki, "Oxygen Content in $\beta-\mathrm{Si}_{3} \mathrm{~N}_{4}$ Crystal Lattice," J. Am. Ceram. Soc., 82 [11] 3263-65 (1999).

${ }^{10} \mathrm{~A}$. Thomas and G. Müller, "Determination of the Concentration of Oxygen Dissolved in the AlN Lattice by Hot Gas Extraction from AlN Ceramics," J. Eur. Ceram. Soc., 8, 11-19 (1991).

${ }^{11}$ S. Nakahata, K. Sogabe, T. Matsuura, and A. Yamakawa, "Electron Spin Resonance Analysis of Lattice Defects in Polycrystalline Aluminum Nitride," J. Am. Ceram. Soc., 80 [6] 1612-14 (1997).

${ }^{12}$ A. Stesmans and G. Van Gorp, " $\mathrm{Si} \equiv \mathrm{Si}_{3}$ Defect at Thermally Grown (111)Si/ $\mathrm{Si}_{3} \mathrm{~N}_{4}$ Interfaces," Phys. Rev. B: Condens. Matter, 52 [12] 8904-20 (1995).

${ }^{13}$ M. Okazaki and K. Toriyama; unpublished work (1999).

${ }^{14}$ M. Kitayama, K. Hirao, M. Toriyama, and S. Kanzaki, "Control of $\beta-\mathrm{Si}_{3} \mathrm{~N}_{4}$ Crystal Morphology and Its Mechanism: I. Effect of $\mathrm{SiO}_{2}$ and $\mathrm{Y}_{2} \mathrm{O}_{3}$ Ratio," J. Ceram. Soc. Jpn., 107 [10] 930-34 (1999).

${ }^{15}$ D. R. Clarke and G. Thomas, "Grain Boundary Phases in Hot-Pressed $\mathrm{MgO}$ Fluxed Silicon Nitride," J. Am. Ceram. Soc., 60 [11-12] 491-95 (1977).

${ }^{16}$ W. E. Lee and G. E. Hilmas, "Microstructural Changes in $\beta$-Silicon Nitride Grains upon Crystallizing the Grain-Boundary Glass," J. Am. Ceram. Soc., 72 [10] 1931-37 (1989) 